\title{
ISOKINETIC STRENGTH OF SHOULDER INTERNAL AND EXTERNAL ROTATORS IN CRICKET BOWLERS
}

\begin{abstract}
The strength of the shoulder internal and external rotators in cricket bowlers, may not be sufficient to cope with the demands of bowling. As very little research has been done on cricketers, this study was done to establish the isokinetic strength profile of the shoulder internal and external rotators in cricket bowlers.

Isokinetic, shoulder rotational strength was evaluated in thirty male

MABASA XM, MSc${ }^{1}$; STEWART A, $M^{\prime} C^{1}$; FLEISHMAN C, MSc ${ }^{1}$

${ }^{1}$ Department of Physiotherapy, Faculty Health Sciences University of the Witwatersrand. cricket volunteers with a mean age of 23.9 years and mean body weight of $70.3 \mathrm{kgs}$. The Cybex 340 dynamometer multi joint system was used to collect data on shoulder rotation strength in a standing neutral position. Data were collected at four different speeds (60,90,180 and 300deg/sec) and were computed for peak torque values for internal and external ratios for both dominant and non dominant shoulders.

The results showed no statistically significant difference in the mean shoulder rotational torque between the bowling and non-bowling shoulders for external rotation $(p>0.05)$, and indicated statistically significant differences in the mean shoulder rotational torque between the bowling and non-bowling shoulders for internal rotation ( $p<0.05)$. There was a significant decrease in isokinetic peak torque production for the external/internal rotator muscles as the speed of contraction increased ( $p<0.05)$. The peak torque ratio for the external/internal rotator muscles of the bowling arm were significantly less than of the non-bowling arm ( $p<0.05)$. These findings suggest that the strength ratios of the bowling arm need to be considered when managing young cricketers and their injuries.
\end{abstract}

KEY WORDS: SHOULDER ROTATORS, PEAK TORQUE VALUE, CRICKET BOWLER, ISOKINETIC STRENGTH RATIO.

\section{INTRODUCTION}

Cricket has traditionally been regarded as a sport that is relatively injury free, although classified as a sport with a 'moderate' injury risk (Stretch 1995). Over the past two decades case reports and studies of incidents of cricket injuries indicate an increase in injuries (Stretch 1995).

Cricket is widely played throughout this country, yet there is little research done on the varied aspects of the game (Smith 1992). The back and shoulder seem to be the most affected by injury. Many authors assume that this is probably because of the complex motor skills, the anthropometric profile and body composition of cricketers (Stretch 1995).

In the clinical setting physiotherapists see athletes complaining of various shoulder problems as a result of throwing sports, an example being cricket. Numerous isokinetic studies of shoulders in other overhead sports especially in baseball have been carried out. No literature is available on isokinetic strength studies in cricket bowlers and fielders. It would be of clinical value to know if there is a relationship between the isokinetic strength profile of the shoulder muscles and injuries in cricket bowlers and fielders. As there seems to be an increase in the number of shoulder injuries (Stretch 1995), the strength of the shoulder rotator muscles may be a factor. This is stated bearing in mind the variety of factors which could lead to shoulder injuries in cricketers.

The distraction forces at the glenohumeral joint during the acceleration to the ball release phase of throwing is one to 1.5 times that of body weight (Wilke et al 1993; Sirota et al 1997). The velocity produced by cricket bowlers varies from $70 \mathrm{~km} / \mathrm{h}-140 \mathrm{~km} / \mathrm{h}$ in fast bowlers (Eastaway 1993).

This has an implication for the dynamic balance that exists between shoulder function and stability (Eastaway 1993). In order to achieve high speeds and good control there should be a balance between the strength and stability of the shoulder (Davis 1992; Fleisig et al 1996).
This study was designed to determine and quantify the isokinetic strength profile of the internal and external rotators of the shoulders in cricket bowlers.

The objectives of this study were:

- to determine the isokinetic strength of the shoulder internal and external rotators in cricket bowlers.

- to establish the ratio of external to internal rotation in the dominant arm.

- to compare the external and internal rotator strength ratio between the dominant and non-dominant arms.

\section{SUBJECTS}

Thirty male volunteers aged between 18 and 30 years who had consistently played club cricket over the previous

\section{CORRESPONDENCE TO:}

XM Mabasa

P.O. Box 2721,

Joubert park 2044,

South Africa.

Tel: (011) 683-4244

Fax: (011) 683-6613 
two years were included in this study. Ethical clearance for this study was obtained from the Human Ethics Committee of the University of the Witwatersrand, protocol number: M990414. The subjects were recruited through their coaches. The subject population was predominantly fast bowlers. The procedure of the test was clearly explained to each subject and signed informed consent was obtained. The subjects were asked to complete a health questionnaire to ascertain whether there was any neck or shoulder pathology present. Four subjects were excluded because of their previous injuries. Information on height, weight, dominant side and normal throwing routine was obtained prior to testing. Subjects with a history of upper limb and neck pathology or symptoms of pain before or during the test were excluded from the study.

\section{MATERIALS}

The Cybex 340-isokinetic-dynamometer multi joint system with a computer and a printer was used.

\section{PROCEDURE}

Each subject was tested in standing with the shoulder in 45 degrees abduction in the scapula plane and 90 degrees elbow flexion as described in Soderberg and Blaschak (1987). This position ensures that the joint is in the neutral position to avoid any mechanical advantage to certain muscle groups. The machine axis was aligned at 75 degrees to the sagittal plane coinciding with the longitudinal axis of the humerus. The lever arm was adjusted to align the olecranon with the machine axis. The subjects grasped the handgrip in a neutral forearm supination/ pronation position. A forearm stabilisation pad was used to prevent any discomfort that can be caused by the velcro strap and lever arm during all tests. The forearm was stabilised using velcro straps. The feet remained in contact with the ground to improve the subject's stability.

The same examiner recorded all measurements. An explanation of the testing procedure and equipment was given before the test began. The subject was encouraged to exert maximal effort during the test. All equipment was cali- brated as per the established manufacture's guidelines prior to any testing.

Isokinetic testing was performed sequentially in the following order: 60 deg per second, 90 deg per second, 180 deg per second and 300deg per second. Only the values for peak torque for the internal and external rotation of both shoulders were computed and analysed.

Testing at each velocity consisted of 4 submaximal contractions for warm-up purposes followed by 3 to 4 maximal repetitions. Five maximal repetitions were then performed at $60 \mathrm{deg}$ per second, 90 deg per second, 180 deg per second. Thirty maximal repetitions were performed at $300 \mathrm{deg}$ per second. A 30second rest was given between speeds (Ariki et al 1985).

Subjects were instructed to push and pull as hard as possible until the bell on the machine beeped. The non-dominant arm was tested first and then the dominant arm. All test results were then printed for analysis.

\section{DATA ANALYSIS}

The variables of interest were the ratios of external to internal rotation with respect to peak torque at $60 \% \mathrm{~s}, 90 \%$, $180 \%$ and $300 \%$ s. Summary statistics (mean and standard deviations) for the observed variables and the demographic variables were performed.

The student's one sample t-test was used to test whether the mean torque ratio of internal and external rotator strength is less than $150 \%$ (ratio of 3:2) while the student's paired t-test was used to compare the torque ratios of the dominant and non dominant shoulder's strength. A decrease of 33\% (imbalance of muscles) in a torque ratio of $3: 2$ is clinically relevant (Ivey 1985). The one sample student t-test applied at the 0.05 level of significance had power in excess of $90 \%$ when comparing the mean ratio in the study group with the acceptable value of $150 \%(3: 2)$ and also when comparing dominant and non dominant shoulders.

\section{RESULTS}

Table 1: Demographic data of subjects $(\mathrm{N}=30)$.

\begin{tabular}{|l|c|c|c|}
\hline & Mean & SD & Range \\
\hline Age (years) & 23.9 & 4.8 & $17-30$ \\
\hline Height (cm) & 174.4 & 12.6 & $150-180$ \\
\hline W eight (lbs) & 154.7 & 4.0 & $100-200$ \\
\hline W eight (kgs) & 70.3 & 1.8 & $45-90$ \\
\hline
\end{tabular}

$\mathrm{SD}=$ standard deviation

26 right dominant and four (4) left dominant. Twenty six subjects were right dominant and four were left dominant.

Table 2: Comparison of mean torque expressed in percentages of internal rotation and external rotation.

\begin{tabular}{|l|c|c|}
\hline Test speed (deg/ sec) & Dominant Torque ratio (\%) & p-value (O ne sample t-test) \\
\hline $60 / \mathrm{s}$ & $136.10 \pm 24.64$ & 0.01 \\
\hline $90 / \mathrm{s}$ & $141.14 \pm 36.82$ & 0.21 \\
\hline $180 / \mathrm{s}$ & $146.29 \pm 42.25$ & 0.64 \\
\hline $300 / \mathrm{s}$ & $143.99 \pm 42.49$ & 0.45 \\
\hline & N on Dominant & \\
\hline $60 / \mathrm{s}$ & $146.59 \pm 26.20$ & 0.52 \\
\hline $90 / \mathrm{s}$ & $148.17 \pm 30.91$ & 0.75 \\
\hline $180 / \mathrm{s}$ & $153.63 \pm 34.38$ & 0.58 \\
\hline $300 / \mathrm{s}$ & $156.33 \pm 51.43$ & 0.51 \\
\hline
\end{tabular}

At $60^{\circ}$ for the dominant shoulder the torque ratio was found to be significantly less than $150 \%(p=0.01)$. The standard deviation seems high, however, in all cases, the coefficient of variation was less than $35 \%$. This is an acceptable number as quoted by Gregory (1975). 
Table 3: The comparison of mean torque ratios for shoulder external and internal rotation between the dominant and non dominant bowling arms.

\begin{tabular}{|l|l|l|}
\hline Test speed (deg/ sec) & Dominant arm Torque ratio & p-values (One sample t-test) \\
\hline $60 / \mathrm{s}$ & $0.68 \pm 3.50$ & 0.65 \\
\hline $90 / \mathrm{s}$ & $0.67 \pm 3.60$ & 0.96 \\
\hline $180 / \mathrm{s}$ & $0.65 \pm 3.56$ & 0.96 \\
\hline $300 / \mathrm{s}$ & $0.67 \pm 4.14$ & 0.60 \\
\hline & Non Dominant arm & \\
\hline $60 / \mathrm{s}$ & $0.74 \pm 6.50$ & 0.03 \\
\hline $90 / \mathrm{s}$ & $0.73 \pm 10.54$ & 0.18 \\
\hline $180 / \mathrm{s}$ & $0.70 \pm 4.95$ & 0.05 \\
\hline $300 / \mathrm{s}$ & $0.71 \pm 6.21$ & 0.05 \\
\hline
\end{tabular}

The mean torque ratio for the non-dominant arm was significantly $(p<0.05)$ higher than the dominant side. There was a tendency towards greater external-internal rotation ratios in the non-dominant arm. The mean torque ratios decreased as the speed of contraction increased.

Table 4: Comparison of mean torque values between dominant and non-dominant bowling arms for shoulder internal and external rotation $(\mathrm{N}=30)$.

\begin{tabular}{|l|l|l|l|}
\hline \multicolumn{4}{|c|}{ Internal rotation } \\
\hline $\begin{array}{l}\text { Test speed) } \\
\text { (deg/sec }\end{array}$ & Dominant & Non Dominant & $\begin{array}{l}\text { p-value } \\
\text { (paired t-test) }\end{array}$ \\
\hline $60 / \mathrm{s}$ & $32.56 \pm 8.02$ & $29.60 \pm 6.93$ & 0.03 \\
\hline $90 / \mathrm{s}$ & $33.31 \pm 15.16$ & $30.62 \pm 9.33$ & 0.18 \\
\hline $180 / \mathrm{s}$ & $29 \pm 10.55$ & $27.10 \pm 8.02$ & 0.05 \\
\hline $300 / \mathrm{s}$ & $26.17 \pm 6.21$ & $23.79 \pm 7.80$ & 0.05 \\
\hline & \multicolumn{2}{|c|}{ External rotation } \\
\hline $60 / \mathrm{s}$ & $22.24 \pm 7.35$ & $21.92 \pm 4.70$ & 0.65 \\
\hline $90 / \mathrm{s}$ & $22.38 \pm 7.53$ & $22.41 \pm 8.22$ & 0.96 \\
\hline $180 / \mathrm{s}$ & $18.90 \pm 5.47$ & $18.86 \pm 5.17$ & 0.96 \\
\hline $300 / \mathrm{s}$ & $17.41 \pm 4.95$ & $17 \pm 4.95$ & 0.60 \\
\hline
\end{tabular}

Values are in foot-pounds(ft/ lbs.)and standard deviation (SD).

There was a statistically significant difference in mean torque values $(p<0.05)$ for the dominant-non-dominant pair, for internal rotation except at $90 \infty / \mathrm{s}(p>0.05)$.

There was no statistically significant difference in mean torque values $(p>0.05)$ for any dominant -non-dominant pair for external rotation.

There was a statistically significant $(p<0.05)$ decrease in peak torque as the limb velocity increased in both arms. The internal rotation torque values were significantly greater $(p<0.05)$ than external rotation in both the dominant and non dominant shoulders.

\section{DISCUSSION}

To our knowledge after an extensive literature search, this is the first study of isokinetic concentric muscle strength in cricket bowlers.

The concentric external rotation strength of the dominant and nondominant shoulder rotators showed no significant difference in mean torque values. There was a trend toward greater mean torque in the dominant shoulders.
Alderink and Kuck (1986), Sirota (1997) and Hinton (1988) also found no significant difference in peak torque values in their studies of high school and college pitchers between throwing and non throwing shoulders for external rotator muscles. Wilke et al (1993) showed a trend towards increased external rotator strength in the nonthrowing shoulder of professional baseball pitchers. The similarity of isokinetic strength of external rotators between dominant and non-dominant shoulders is somehow surprising as one would assume that the bowling/throwing arm should be weaker than the non-bowling arm. A possible explanation is that the shoulder retractors develop a stretch weakness (Kendal and Kendal 1952) that is due to the exaggerated, protracted, depressed posture, which the bowling side shoulder girdle tends to assume during the deceleration phase. A large eccentric load is placed on the posterior rotator cuff. Eccentric loading has been shown to cause intramuscular connective tissue tearing (Davies, 1992) which can lead to a cycle of chronic inflammation and muscular weakness. The results are consistent with the available literature on other overhead studies.

The concentric internal rotator muscle strength showed significant differences in mean torque between the dominant and non-dominant shoulders for cricket bowlers in this study except at $90 \%$ where there was no significant difference. These results also coincide with the findings of Hinton (1988) who reported significant increases in internal rotator muscle strength in the dominant shoulders of high school pitchers (Alderink and Kuck 1986, Sirota et al 1993 and Wilke et al 1993). Ivey et al (1985) also found significant difference in the internal rotational torques in baseball pitchers and people who did not play baseball which is similar to the results found at $90 \%$ for this study. It is not surprising to see that the isokinetic strength of internal rotators between dominant and non-dominant shoulders is different as the internal rotation muscles undergo a plyometric contraction with each bowling action. Plyometrics occurs where a muscle is maximally stretched and then followed by a sudden explosive contraction. It could also be that the internal rotators were also receiving overflow from the larger and stronger lower extremities of the linking side (Sirota et al 1997).

The mean torque ratio for the nondominant side was significantly $(\mathrm{p}<0.05)$ higher than the dominant side. This could have been due to the fact that there was a significant difference in internal rotation peak torque and no significant 
difference in external rotation peak torque between dominant and non-dominant sides. It is known that there is a difference in isokinetic shoulder strength of approximately $10 \%$ when comparing the dominant to the non dominant sides which naturally occurs because people tend to favour their dominant sides (Kendal and Kendal 1952). As discussed above we suggested that the external rotation strength is lower on the dominant side and we think that could have lead to lower mean torque values on the dominant side.

\section{SUMMARY}

This study showed that there were muscular imbalances between the external and internal rotator muscles mainly on the dominant side. It also showed side to side differences in muscle strength ratios. Although there is no norm of shoulder external rotator strength in cricketers, the implication of this study is that the shoulder external rotator strength on the dominant side appears to be low. When reading the results of this study one must keep in mind the controversy of the optimal testing position for internal and external rotation strength (Falkel et al 1987, Soderberg and Blaschek 1987, Walmsley and Szybbo 1987). In addition the small number of subjects and the lack of literature on isokinetic strength of internal and external rotation of cricket bowlers implies caution when interpreting the results of this study.

We recommend that further research be done using larger samples involving provincial and national level cricket bowlers, to study different types of bowling and to compare different muscle contractions, as well as injured and uninjured bowlers.

Physiotherapists need to consider the strength ratios of the shoulder rotators when preventing injuries in cricketers and in their rehabilitation programmes.

\section{CONCLUSION}

There was no significant difference in mean torque produced for external rotational strength between the dominant and non dominant shoulders.

There was a significant difference in mean torque produced for internal rota- tional strength between the dominant and non dominant shoulders.

There was a significant difference in mean peak torques produced between internal rotation and external rotation strength.

The external to internal rotator muscle strength ratio in the mean torques produced by the dominant and non dominant shoulders were significantly different.

\section{REFERENCES}

Alderink G J, Kuck D J 1986 Isokinetic shoulder strength of high school and college aged pitchers. Journal of Orthopaedic Sports Physical Therapy 7(4): 163-172.

Ariki PK, Davies GJ, Siewert MW 1985 Optimum rest interval between isokinetic velocity spectrum rehabilitation speeds (abstract). Physical Therapy 65(5):735.

Davies G J 1992 A compendium of isokinetic in clinical usage, Lacrose. W1. Sand Publishers 4th Edition. 216-222.

Eastaway R 1983 Cricket explained, Cricket rules, New York: St Martin's press, 1st US Ed 1-23.

Gregory 1975 Statistical Methods and the geographer, 3rd Edition Longman UK.

Falkel J E, Murphy TC, Murray TF 1987 Prone positioning for testing shoulder internal and external rotation on Cybex II isokinetic dynamometer. Journal of Orthopedic Sports Physical Therapy 8(7): 368-370.

Fleisig GS, Barrentine SW, Escamilla RF, Andrew JR 1996 Biomachanics of overhand throwing with implications for injuries. American Journal of Sports Medicine. 21(6) 421-37.

Hinton RY 1988 Isokinetic evaluation of shoulder rotational strength in high school baseball pitchers. American Journal of Sports Medicine, 16(3):216-222.

Ivey FM, Calhoun JH, Rusche K, Bierschenk J 1985 Isokinetic testing of shoulder strength: Normal values. Archives of Physical Medicine and Rehabilitation 66:384-386.

Kendal HO, Kendal FP, Boynton PA 1952 Posture and pain. Baltimore, Williams and Wilkins. 2nd edition 291-292.
Sirota SC, Malanga GA, Eischen JJ, Laskowki ER 1997 An eccentric and concentric strength profile of shoulder external and internal rotator muscles in professional baseball pitchers. American Journal of Sports Medicine 25(1):59-65.

Smith C 1992 Cricket injuries while on tour with the South African team in India. South African Journal of Sport Medicine 7(1): 4-8.

Soderberg GJ, Blaschek MJ, 1987 Shoulder internal and external rotation peak torque production through a velocity spectrum in differing position. Journal of Orthopaedic Sports Physical Therapy 8(11):518-24.

Stretch RA 1995 The incident and nature of injuries in first-league and provincial cricketers. South African Journal of Sports Medicine 83(5): 339-42.

Walmsley RP, Szybbo C 1987 A comparative study of the torque generated by the shoulder internal and external rotators in different positions and at varying speeds. Journal of Orthopaedic Sports Physical Therapy 9: 217-222.

Wilke KE, Andrews JR, Arrigo CA, Keirns MA, Erber DJ 1993 The strength characteristics of internal and external rotator muscle in professional baseball pitchers. American Journal of Sport Medicine. 21(1):61-66. 


\section{The Intensive Care Unit Manual - Paul N. Lanken (2001)}

Published by W.B. Saunders Company ISBN 0-7216-2197-X

A fter reading the first chapter of this 98-chaptered book, on the Approach to Acute Respiratory Failure, I finally understood the mechanism of respiratory failure, properly, for the first time in my ten year career in respiratory physiotherapy. Thereafter I was completely hooked on this book and couldn't wait to get home at night to continue reading it!

This manual was written for staff working in medical, surgical, cardiac and neurosurgical intensive care units (ICU) to help them perform a wide variety of treatments successfully in any critical care situation. This is a comprehensive and concise manual, which offers practical guidance to its users through the use of informative and clinically relevant flow charts, tables and diagrams. The chapter length varies from 6 pages (Thoracic Trauma) to 17 pages (Acute
Coronary Syndromes) and the chapters follow a logical progression. The basic ICU principles and practices (ie Mechanical Ventilation, Hemodynamic Function Assessment, Septic Shock) are followed by problem-based chapters focusing on problems arising after ICU admission (ie Acute Arterial Desaturation, Chest Pain, Diarrhea) and the final section covers common ICU admitting diagnoses (ie Neurological, Surgical, Trauma). The references used throughout this manual range from the late 1980's to 2001.

Numerous academics contributed to this well-written and well-assembled manual. The largest contributions were from Drs Paul N. Lanken (10 chapters), Scott Manaker (6 chapters) and C. William Hanson III (5 chapters) from the Hospital of the University of Pennsylvania and is a testimony of their own clinical expertise and knowledge in the field of Intensive Care.

I thoroughly enjoyed the sections on Rehabilitation Interventions, Swallowing and Communication Disorders, The Challenge to Wean Patients, End-of-Life Care and Neuromuscular Weakness to name but a few. The emphasis that the authors place on the multi-disciplinary team approach to patient care is heartwarming! The chapter on Acute Respiratory Distress Syndrome would have been even more informative if the recent advances in the use of Liquid Ventilation in this disease were mentioned. More practical guidelines on the approach to patients' families regarding organ donation and transplantation would have been useful in the chapter on Brain Death.

Even though this manual was written in the USA the practices described correlate well with current ICU practices in the UK and SA. I gladly recommend The Intensive Care Unit Manual to all Respiratory Physiotherapists!

HELEEN VAN ASWEGEN M Sc Physiotherapy ICU Lecturer - Wits University

\section{PRACTICE FOR SALE}

Amanzimtoti: Growing, well established physiotherapy practice, based in doctor's rooms in the heart of Amanzimtoti and serving the local hospital in all conditions. Equipment La, US, if included R60 000.00. Contact Mary, Cell: 082 824-8512.

Pinetown: Well established one-man practice for sale. Owner relocating. Tel: (031) 709-2345 or 083 457-8910.

\section{SITUATIONS VACANT}

Klerksdorp/North West: Dynamic physiotherapist needed for an interesting and varied established practice on a full-time basis. The work includes hospital and rooms patients. Contact Marna, Tel: (018) 468-3430.

Brakpan: Muriel Brand School, Physio needed at CP school. Contact Sonet Fowler, Tel: (011) 817-9320 (w), (011) 744-1355 (h).

\section{Physotherapist Position-Texas,} USA, State-of-the-art aquatic physical therapy clinic seeks physiotherapists with 3+years experience, manual therapy and aquatic physical therapy training. Full-time, Salary \& benefits. Our company sponsors foreign workers (for the green card), permanent residents. Fax your resumé to (409) 737-9618, or e-mail jerryg@AquaticCare.net, Website: www.AquaticCare.net, Aquatic Care Programs, Inc. 1910 First St. Humble, Texas (Houston) 77338.

Nelspruit: Dinamiese algemene praktyk het een pos beskikbaar vir 'n fisioterapeut om so gou moontlik te begin. Tel: (013) 752-6657, Cell: 082 820-7942.

\section{Northern Suburbs - Kenridge, Durbanville: An experienced,} confident and fully bilingual physiotherapist needed for a permanent full-day position at a busy general practice, as from beginning of July 2002. Please contact Karin at: (021) 913-6262 (during office hours), (021) 913-4034 (after 20h00) Cell: 083 280-2233.
Brooklyn: Halfdag/ voldag kamerwerk. Ideale werksomstandighede. Kontak Lise, Tel: (012) 346-1266.

\section{Botswana - Gaberone:}

Experienced physiotherapist required for out-patients practice. Should have experience with sij, dry needling and sports injuries. From August to October 2002. Accommodation available. Contact Tanya, Tel: (09267) 393-4433.

Somerset West: Full-time post in OMT/ Rehabilitation and Cardiothoraeic. Will favour academic pursuit. Contact: (021) 862-3458.

KZN/North Coast: Mseleni Hospital near beautiful Lake Sibhayi offers a therapist post (OT or PT). Rewarding Hospital/Community work in rural area. Work includes all aspects of rehabilitation. Post available immediately - last applications May 2002. Contact Sunette, Tel: (035) 574-1004, Fax: (035) 574-1654, e-mail: sunette@mseleni.co.za

\section{WORK WANTED}

Pretoria: Available for locums. Contact Sandra, Cell: 082 294-9718, Tel: (012) 804-5099. 